\title{
INVESTIGATION OF DISEASES OF JUVENILE CATLA FROM CULTURE POND FARMING CONDITION IN MYMENSINGH
}

\section{R. Das ${ }^{1 *}$ and K. J. Chandra ${ }^{2}$}

${ }^{1}$ Bangladesh Fisheries Research Institute, Floodplain Sub station, Santaher, Bogra; ${ }^{2}$ Department of Aquaculture, Bangladesh Agricultural University, Mymensingh, Bangladesh

\begin{abstract}
Investigation on health conditions and diseases of juvenile catla (Catla catla) was carried out for clinical and histopathological observations from different farms of Mymensingh region. A total of eight (8) farms, four Government (Govt.) and four Private (Pvt.) fish farms were selected for the study. The Indian major carp - catla was examined during June, 2010 to May, 2012. Monthly samplings were carried out with 5 fishes from each farm. Altogether 960 fish hosts were examined during the study period. Water quality parameters such as temperature, dissolved oxygen, $\mathrm{pH}$, ammonia, hardness, alkalinity, transparency and depth of water etc. were taken and management practices were investigated fortnightly interval. These were almost similar for all experimental ponds. The risk of being infestation by parasites of catla significantly $(p<0.001)$ increased when the water quality parameters were not maintained the optimum level. Clinical examination of fishes was also carried out for any kind of abnormalities at monthly intervals. For histopathological studies skin, muscle, gill, liver and kidney were collected, processed and stained in Haematoxylin and Eosin. Histologically, catla of different fish farms were more affected in colder months (October to January). Structures of fish organs were normal from March to July. In the months of September, minor pathologies were found to be started and in the months of February the pathological condition of fish gradually reduced. Pathological changes like necrosis, fungal granuloma, protozoan and monogenean cyst, vacuolation, melanomacrophase, haemorrhage, hypertrophy, hyperplasia and clubbing were recorded in all the investigated organs. Among them fish gills and skin were more affected followed by liver and kidney. Again when considered individual fish farm, fish of Pvt. Fish farms were more affected than others. The study showed that severity of clinically and pathologically changes were gradually increased in November to January. During the period mixed infection of protozoa, monogenea and argulus were noticed in catla of the investigated farms.
\end{abstract}

Key words: Pathology, disease, culture ponds, catla, Mymensingh.

INTRODUCTION

From the historical facts, fish culture in ponds was started from China (Ling, 1974). Indian major carps involved in aquaculture system from immemorial time in South-east Asian countries, including Bangladesh. Polyculture is the system in which fast growing compatible species of different feeding habits are stocked in different proportions in the same pond (Jhingran, 1976) has been practicing from the very beginning of the fish culture in China and in Indian sub-continent.

About thirty commercially important fish species are available in Bangladesh, among which, carps is one of the most commonly cultured groups of fishes in Asia (Uddin et al., 1994). Mainly catla (Catla catla), rui (Labeo rohita), Mrigal (Cirrhinus cirrhosus and (Cyprinus carpio) are very important fishes which are cultured throughout the country. They are considered as the most economically important fishes of Bangladesh because they are nutritious and delicious, have high market demand and their fry and fingerlings are easily available for culture. They are fast growing with minimum mortality, because they have disease resistance capability and can also tolerate wide range of environmental parameters (Adhikary et al., 2009). These fishes have a very wide acceptance among the most of the farmers of the country. Mainly catla is native to Asia. Among the Indian major carps, the catla is an important favorite indigenous fish of Bangladesh. It is easy to culture, with disease resistance capacity and can tolerate a wide range of environmental conditions. The fish culture system in Bangladesh is mostly extensive type and with introduction of intensive system, fish farmers are encouraged due to increased fish production. Intensive culture system with very high stocking densities, poor water qualities is encountered with much of the disease problems. Disease among culture fish can cause death, poor growth and food conversion which increased production costs and interrupted production schedule (Austin and Austin,

*Corresponding e-mail address: drd4272@yahoo.com 


\section{R. Das and K. J. Chandra}

1987). Disease has become a major problem in fish production in culture system and wild condition in Bangladesh (Rahman and Chowdhury, 1999). Several histopathological studies have been done on freshwater small indigenous fishes (Roy et al., 2006; Parveen et al., 2005), though only few works have been done on major carps. So the present work was undertaken in order to diagnose diseases of cultured juvenile Catla (C. catla) fingerlings in Govt. and Pvt. fish farms of Mymensingh district, Bangladesh. The major objective of the study is to investigate the diseases of juvenile catla in Mymensingh region.

\section{MATERIALS AND METHODS}

The study was conducted for a period of 24 months from June 2010 to May 2012. For histopathological investigation eight different fish farms, 4 Government Farm (Bangladesh Fisheries Research Institute (BFRI), Fish Seed Multiplication Farm (Maskanda), Fish Seed Multiplication Farm (Shambhugonj), Fish Seed Multiplication Farm (Gouripur)) and 4 Private farms (Brahmaputra Fish Farm, Deshbondhu Fish Farm, Pankouri Fish Farm and Sornolota Fish Farm) were selected.

Water quality parameters like temperature, dissolved oxygen and $\mathrm{pH}$ was determined by using thermometer, DO meter and $\mathrm{pH}$ meter from the eight mentioned farms. Transparency of the ponds was measured by a Secchidisc of $30 \mathrm{~cm}$ in diameter and depth of water was measured by a ribbon of $\mathrm{cm}$. Ammonia, alkalinity and hardness was measured by Bromophenol/blue indicator and HI: 3 811-0 Solution by Titrimetric method (HI: 3811-0 Alkalinity test kit) respectively. To observe the seasonal infestation, only distinct seasons were used, rainy season: June, July, August, September; winter season: October, November, December, January and summer: February, March, April, May in the experimental period. Similar pattern were also used by several authors (Banerjee and Bandyopadhyay, 2010; Bhiyan et al., 2010; Bhuiyan and Musa, 2008).

During sampling 5 live fishes were collected from every pond with the help of seine net. Immediately fish samples were transported to the Fish Disease Laboratory of the Dept. of Aquaculture, BAU with plastic containers and bags. The young carps or juvenile were examined quickly to observe for parasitic infestation, injury, infection and other abnormal conditions of fish body. Body surface of the host fishes were carefully observed using magnifying glasses and sometimes naked eyes. Some specimens were examined on spot for external parasites with the help of a field binocular microscope.

For histopathological study, monthly sample was collected from various organs such as skin, muscle, gill, liver and kidney of fishes by a sharp scalpel and forceps. Skin-muscle were collected from the place between anterior part of dorsal fin and lateral line and by removing operculum, gills samples were collected. For liver and kidney, fishes were dissected and then portions of liver and kidney were collected. All collected samples were fixed in 10 $\%$ neutral buffered formalin. The amount of fixative was 10 times to bulk of tissue fixed (Humason, 1979).The sizes of the samples were $1 \mathrm{~cm}^{3}$.

The preserved samples were taken out and trimmed by scalpel. Trimmed samples were placed separately in perforated plastic holders and covered by perforated steel covers. Labeling was made with dark pencil (2B) on perforated plastic holders. The samples were then arranged in a steel rack and processed through an automatic tissue processor (SHANDON, CITADEL 1000) for dehydration, clearing and infiltration. Alcoholic series of higher concentration, xylene and paraffin ( 3 series) were used in the processor maintaining at various time schedules as mentioned.

The samples were then embedded with melted wax, steel mold and perforated plastic holder. Proper care was taken for the placement and orientation of stomach and intestine samples in the steel molds during the embedding period. After embedding period the paraffin blocks were placed on a table to be solidified. The blocks were then placed in a refrigerator for half an hour and the steel molds were then separated from the paraffin blocks. Trimming was done from side and surface of the blocks with the help of scalpel and a Microtome Machine (Leica JUNG RM 2035) respectively.

The blocks were then washed with tap water and distilled water repeatedly. Before the final section, sample blocks taken and placed in a deep freeze for at least 30 minutes. The blocks were then sectioned at thickness of 5 micrometers by using the Microtome Machine. The ribbons with section were placed on water bath (Electro thermal, MOUNTING BATH) at a temperature of $40^{\circ} \mathrm{C}$. Suitable section were selected and separated from the ribbons which were finally picked up over glass slides. The sections were then stained with haematoxylin and eosin (H\&E) stains proceeding through various chemicals of different concentrations and time schedule as mentioned. 
After staining the sections were mounted with Canada balsam and covered with cover slips. The prepared sections were kept over a flat surface for 8-10 hours in order to fix the cover slips permanently and then examined under a compound microscope (Olympus, Japan). Photomicrographs of the stained sections were done by using a photomicroscope (Olympus, Model CHS, Japan). Records of structural variations and pathologies were done from the slides and photographs. Comparisons of pathologies and diseases in fish were thus made between the farms and among the various months or seasons of the investigated fish.

\section{RESULTS}

Physico-chemical features such as water temperature, total alkalinity, $\mathrm{DO}, \mathrm{pH}$, total hardness transparency and depth of water of the monthly record showed fluctuations in different months. Water quality parameters are related to disease infestation as they fluctuate more rapidly.

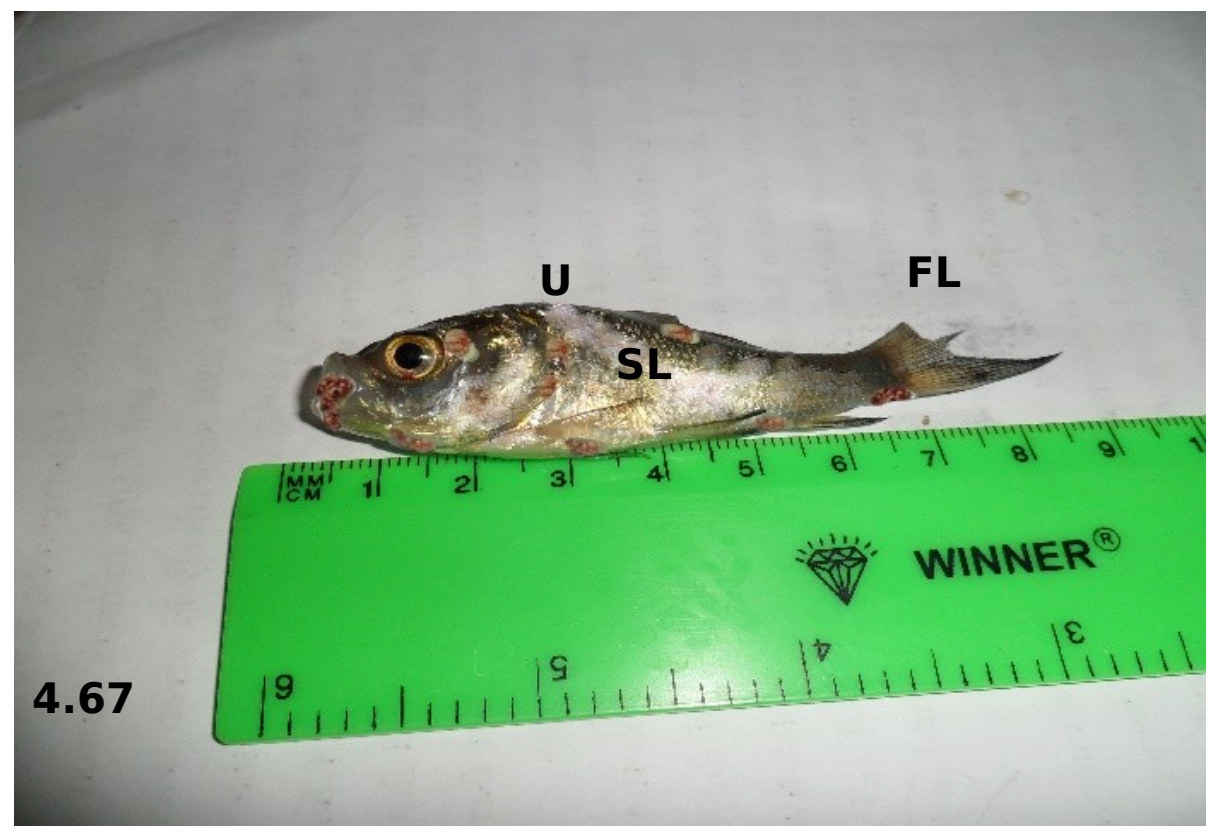

Figure 1. Photograps of clinical signs Catla in December with scale loss (SL), fin loss (FL) and ulcer (U) were seen

Clinically, it was observed that Catla of different fish farms were more affected in colder months (October to January). Structures of fish organs were normal from March to July. In the months of September, minor pathologies were found to be started and in the months of February the pathological condition of fish gradually reduced.

\section{Gill pathology of Catla}

During June and July, both the primary and secondary gill lamellae were arranged systematically and no significant pathological symptoms were observed. In August and September, primary gill lamellae were splitted (arrow) and monogenean (MT) infestation noticed in gill lamellae in BFRI fish farm $\left(\mathrm{P}_{1}\right)$ (Figure 2). Monogenetic trematodes (MT), protozoan cyst (PC) were found attached with primary gill lamellae in Maskanda Govt. fish farm $\left(\mathrm{P}_{2}\right)$ (Figure 3). In October and November, mild hyperplasia (HYP), hemorrhage (H) due to monogenean (MT) infestations were found in primary gill lamellae in Sombhugonj Govt. fish farm $\left(\mathrm{P}_{3}\right)$ (Figure 4). Talengiectasis (T), hyperplasia (HYP) and hemorrhage $(\mathrm{H})$ were noticed in Gouripur Govt. fish farm $\left(\mathrm{P}_{4}\right)$ (Figure 5). In December, secondary gill lamellae were lost (arrow), hyperplasia (HYP), haemorrhage (H), monogenetic treamatodes (MT), protozoan (PC) and microbial cyst (MC) were recorded in Brahmaputra Pvt. fish 


\section{R. Das and K. J. Chandra}

farm $\left(\mathrm{P}_{5}\right)$ (Figure 6). Affected gills showed complete missing of secondary gill lamellae (arrow), infested with monogenean (MT) caused necrosis $(\mathrm{N})$, hypertrophy $(\mathrm{HY})$ and haemorrhage $(\mathrm{H})$ in Deshbandhu Pvt. fish farm $\left(\mathrm{P}_{6}\right)$ (Figure 7). Whereas, in January, affected gill with loss of secondary gill lamellae (arrow), having hypertrophy (HY), haemorrhage $(\mathrm{H})$, due to Trichodina $(\mathrm{Tr})$ (protozoan cyst) infection in Pankouri Pvt. fish farm $\left(\mathrm{P}_{7}\right)$ (Figure 8). Several pathologies were also noticed in February, by monogenetic trematodes (MT) and protozoan cyst (PC). Loss of secondary gill lamellae (arrow) along with hypertrophy (HY), hemorrhage $(\mathrm{H})$ and hyperplasia (HYP) were noticed in Sornolota Pvt. fish farm $\left(\mathrm{P}_{8}\right)$ (Figure 9). However, during March, both the primary and secondary gill lamellae and other cells were healing state and gill lamellae and other parts of gill were more or less in normal fashion in April and May.
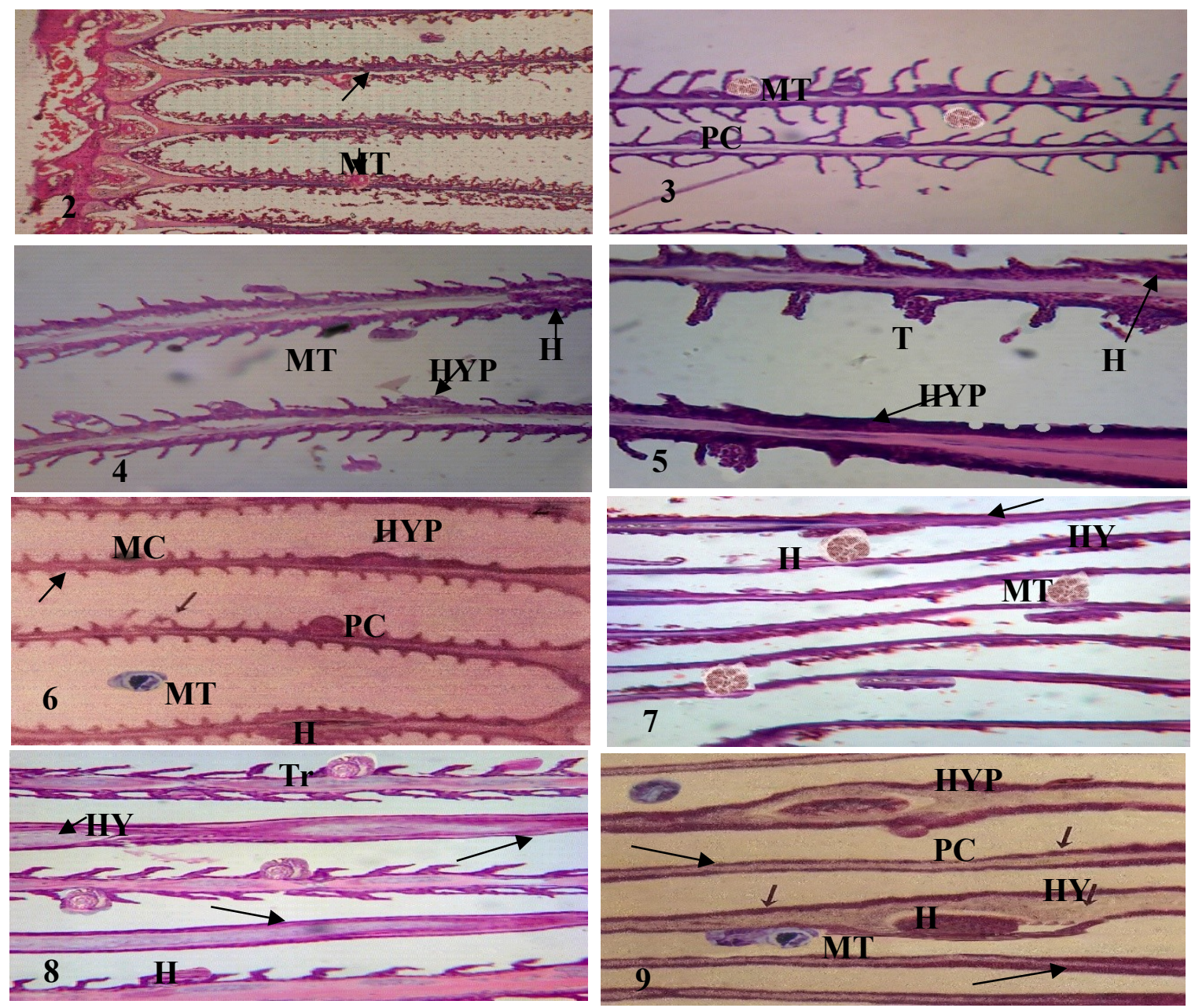

\section{Pathology of skin and muscle of Catla}

In summer (March to July), epidermis, dermis and myotomes of muscles were normal in all carps in all the farms. In August lots of pathologies were observed. Extensive vacuums (V) of sarcoplasm with haemorrhage $(\mathrm{H})$ and Argulus (A) parasites were observed in $P_{1}$ (Figure 10). However, in September, ectoparasitic (MT) lesion showed vacuums (V), haemorrhage $(\mathrm{H})$, infammatory with sarcoplasmic necrosis $(\mathrm{N})$ and epidermis partially lost (arrow) in $\mathrm{P}_{2}$ (Figure 11). Epidermis totally lost (arrow), dermis splitted (DS), vacuum (V), necrosis (N) in muscles and monogenetic trematode (MT) and Argulus (A) infestations were observed in $\mathrm{P}_{3}$ (Figure 12). Epidermal missing (arrow), necrosis (N), fungal hyphae $(\mathrm{FH})$, vacuums $(\mathrm{V})$, monogenetic trematode $(\mathrm{MT})$, protozoan cysts $(\mathrm{PC})$ were observed in skin and muscle in October in $\mathrm{P}_{4}$ (Figure 13). Beginning of winter 
(November to December), epidermal missing (arrow), dermis sloughed off (DS) from muscle, necrosis (N), vacuums (V) and haemorrhage (H) with monogenetic trematode (MT) and protozoan cysts (PC) in skin and muscle in $\mathrm{P}_{5}$ (Figure 14). In January and February, pathologies were epidermis missing (arrow), more severe with ulcerated ectoparasitic (Trichodina) lesion having extensive haemorrhage $(\mathrm{H})$, necrosis $(\mathrm{N})$ and vacuums $(\mathrm{V})$ in the compactum in $\mathrm{P}_{6}$ (Figure 15). Epidermis lost (arrow), dermis splitted (SP), necrosis $(\mathrm{N})$, vacuums (V) occurred due to monogenetic trematode (MT) and protozoan cyst (PC) in $\mathrm{P}_{7}$ (Figure 16). Heavily infected skin and muscles by Lernaea (L) and protozoan cyst (PC) were found in $\mathrm{P}_{8}$ fish farm with necrosis $(\mathrm{N})$ and vacuums $(\mathrm{V})$ in muscles (Figure 17).
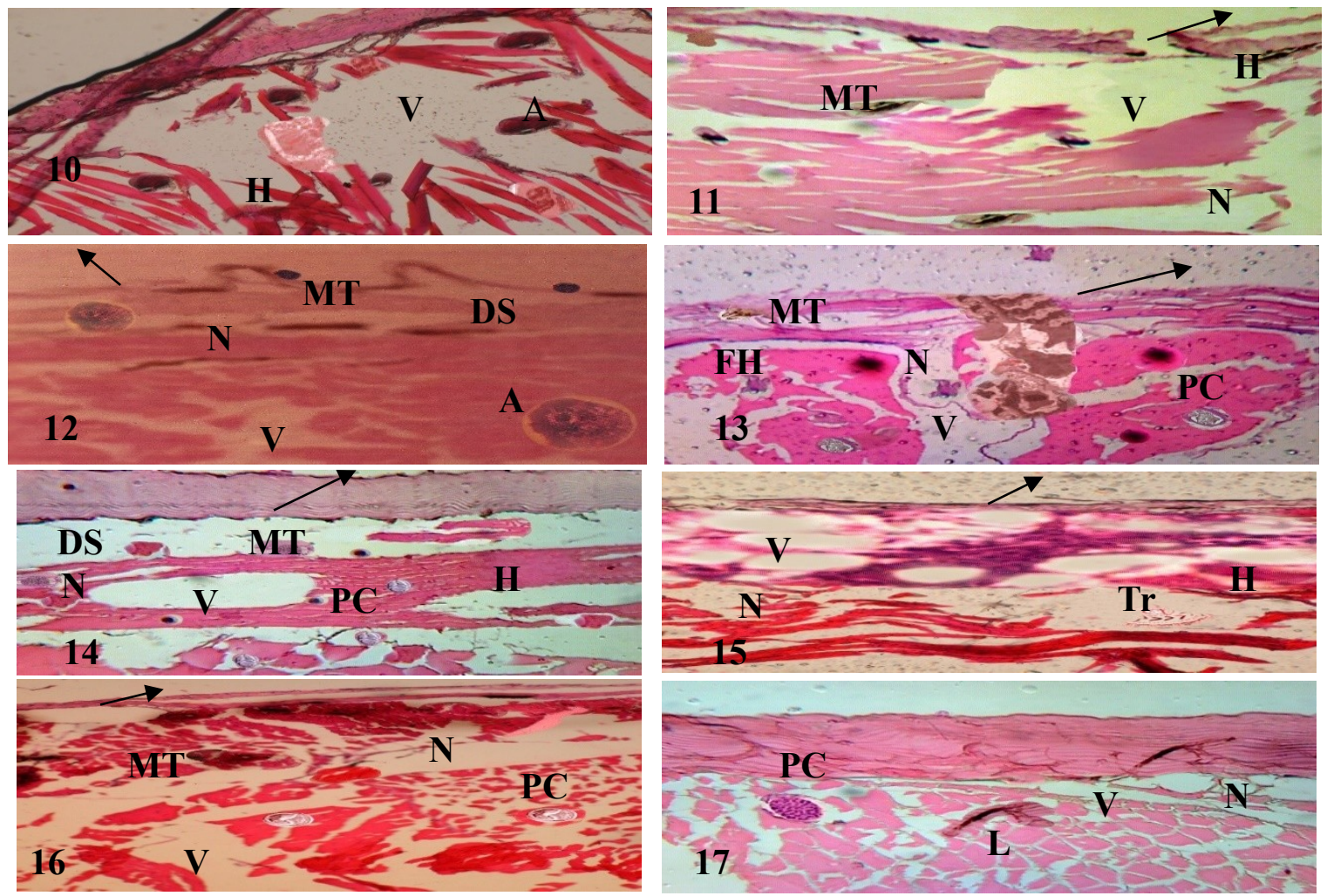

\section{Pathology in liver of Catla}

In June and July, hepatocytes of liver were arranged in normal fashion. There were no significant pathological differences in the structure of liver during this period in all farm fishes. Whereas, during the month of August, liver showed vacuums $(\mathrm{V})$, necrosis $(\mathrm{N})$ haemorrhages $(\mathrm{H})$ and microsporean cyst (MC)in hepatoma in Catla (Figure 18). In September, $\mathrm{P}_{2}$ showed marked necrotic $(\mathrm{N})$ hepatic, hemorrhage $(\mathrm{H})$, pyknosis $(\mathrm{P})$ and vacuums $(\mathrm{V})$ in Catla (Figure 19). Almost similar pathological changes were also found in $P_{3}$ in Catla in October (Figure 20). Whereas, in November, $\mathrm{P}_{4}$ had neoplastic cell $(\mathrm{NP})$, bile duct $(\mathrm{BD})$, vacuums $(\mathrm{V})$, hemorrhage $(\mathrm{H})$, pyknosis $(\mathrm{P})$, bacterial colony $(\mathrm{BC})$ and necrosis (N) in Catla (Figure 21). In December, in $\mathrm{P}_{5}$ farm in Catla had necrosis $(\mathrm{N})$, active vacuums (V), Ilets of langerhens (IL) like particles in the cytoplasm (Figure 22), fat body (FB),vacuums (V) and necrosis (N) were found in $\mathrm{P}_{6}$ (Figure 23), whereas, in January, cord of basophilic hepatocytes (BH), Ilets of langerhens (IL), vacuums (V), necrosis $(\mathrm{N})$,protozoan cyst $(\mathrm{PC})$ and neoplasia $(\mathrm{Np})$ in the cytoplasm were found in $\mathrm{P}_{7}$ (Figure 24) and hemorrhages $(\mathrm{H})$, vacuums $(\mathrm{V})$, necrosis $(\mathrm{N})$ were also found in $\mathrm{P}_{8}$ in January (Figure 25). However, during February and March, hepatocytes and other cells were healing state and hepatocytes and other cells of liver were more or less in normal fashion in April and May. 

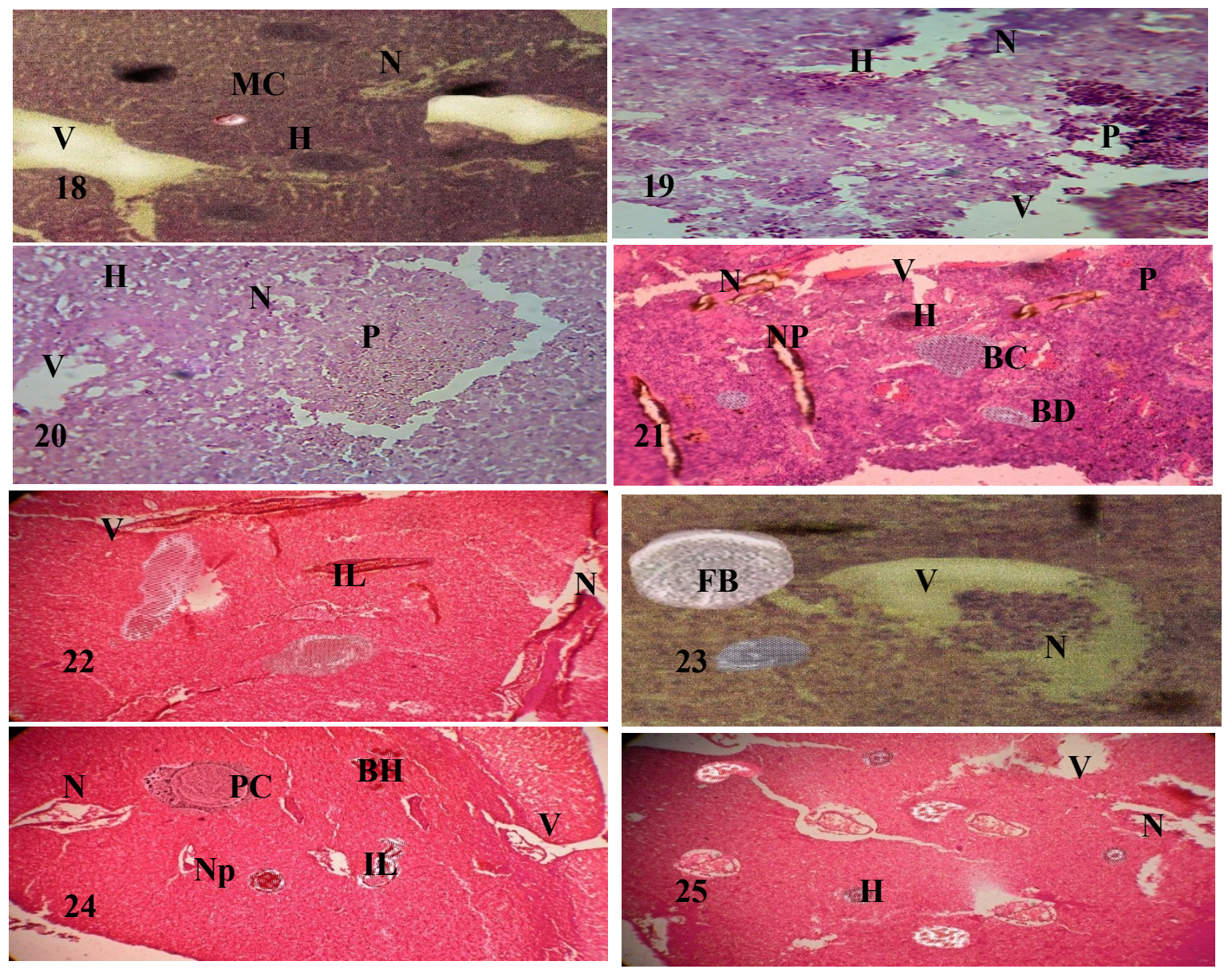

\section{Pathology of kidney in Catla}

Kidney structure was normal in the months of June and July in Catla of $\mathrm{P}_{1}$ and $\mathrm{P}_{2}$ (Figures 26 and 27). In August, Catla intensely affected with degenerated kidney glomerulus (DG) and tubule (DT), melanomacrophage (MMC), eosinophilic colloidal substance (CS), hemorrhage $(\mathrm{H})$ and vacuums $(\mathrm{V})$ in $\mathrm{P}_{3}$ farm (Figure 28). In September, degenerated kidney tubules (DT), necrosis (N), vacuums (V) and pyknosis (P) were observed in $\mathrm{P}_{4}$ in Catla (Figure 29). In October, necrosis $(\mathrm{N})$, wide vacuums $(\mathrm{V})$, hemorrhage $(\mathrm{H})$ and huge number of pyknotic cells $(\mathrm{P})$ were found in Catla in $\mathrm{P}_{5}$ farm (Figure 30). In November, destruction and degenerating of the glomeruli (DG), capillary sclerosis (CS), glomerular nephritis $(\mathrm{GN})$, hemorrhage $(\mathrm{H})$, vacuums $(\mathrm{V})$ and necrosis $(\mathrm{N})$ were found in $\mathrm{P}_{6}$ farm in Catla (Figure 31). Mild necrosis (N), keryolysis (Kl), vacuums (V), keryorhexis (Kh) and pyknosis (P) were observed in Catla of $\mathrm{P}_{7}$ in December (Figure 32). In January and February, degenerated kidney tubules (DT), anomalous conditions of the renal corpuscle (CS), hemorrhage (H) and vacuum (V) in kidney tubule were observed of Catla in $\mathrm{P}_{8}$ farm (Figure 33). Necrotic glomerulus and renal tubules were observed though at healing stage in February and continued it till March. In the month of March, tubule of kidney had hemorrhage $(\mathrm{H})$ and pyknotic cells $(\mathrm{P})$ were also observed in this period. In the months of April and May, tubules of kidney were quite normal in all carp fishes and arranged systematically and no pathological symptoms were detected. 

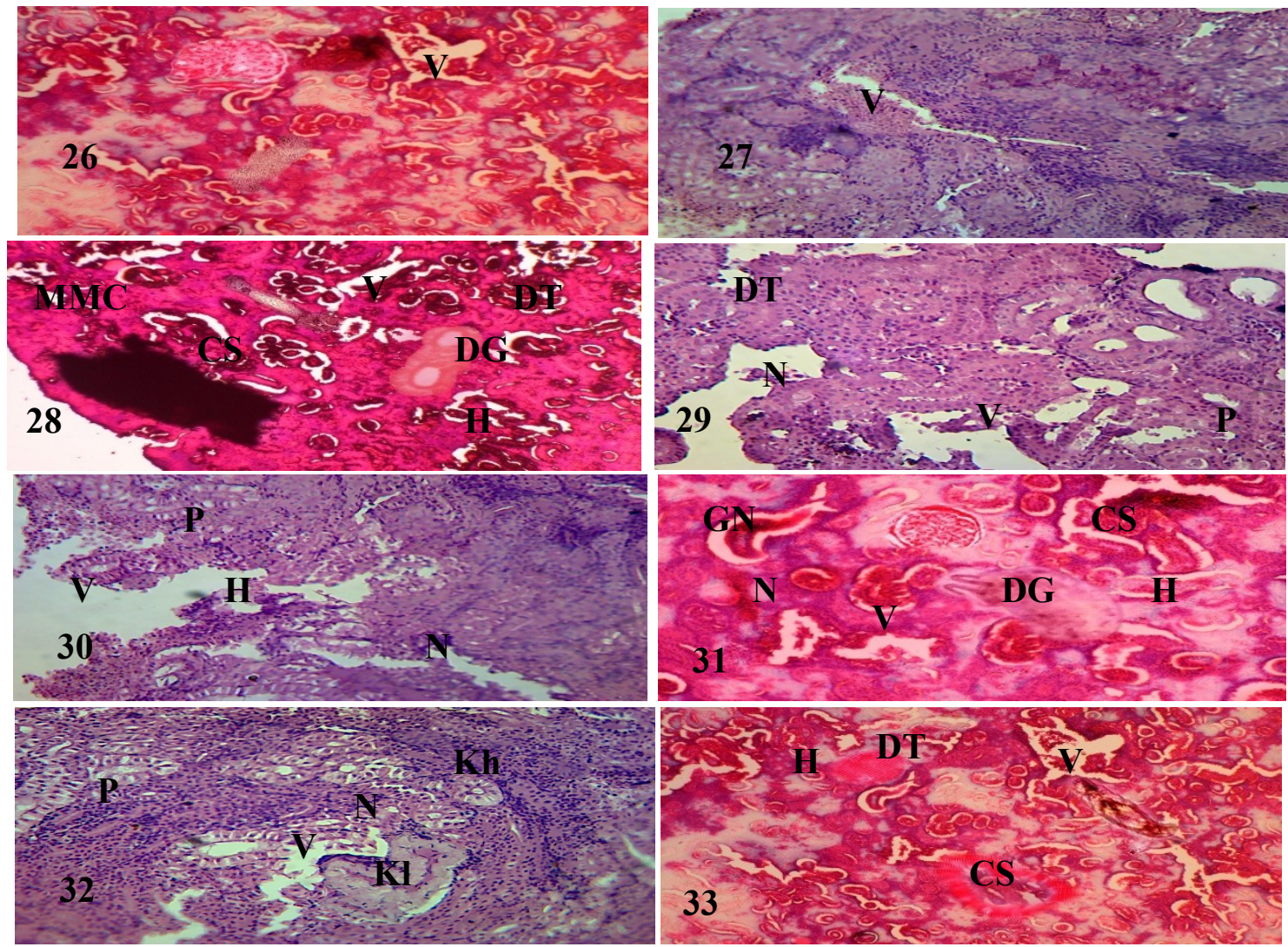

\section{DISCUSSION}

Water quality parameters play important role in disease outbreak in farm fishes. Ectoparasitic prevalence was positively correlated with diseases with the increasing temperature of water (Banerjee and Bandyopadhyay, 2010). The total alkalinity and hardness showed more or less direct relationships with $\mathrm{pH}$ and $\mathrm{NH}_{3}$. More or less inverse relationship was found between DO and ammonia; which had also been observed by Hossain et al. (2007). A close relationship between $\mathrm{pH}$ and carbonate content of water was also observed. The monthly prevalence data revealed that ectoparasitic infection was heavy unionized ammonia was toxic to fish, while the ammonium ion $\left(\mathrm{NH}_{4}+\right)$ was nontoxic (Ahmed et al., 2009). Lower concentration of $\mathrm{pH}$ increases the toxicities of hydrogen sulphide $\left(\mathrm{H}_{2} \mathrm{~S}\right)$, copper and other heavy metals to fish. Fishes are prone to attack of parasites and diseases in acidic waters (Banu and Khan2004). As a result the fishes become weak and infected by parasites. The present data on $\mathrm{DO}, \mathrm{pH}, \mathrm{NH}_{3}$, transparency and hardness are similar to those reported by Shahjahan et al. (2001).

In the current study pathological changes in gills of catla were almost normal in summer season (March to July). Whereas, in rainy and winter season, a gradual increase in the pathological signs such as mild necrosis, hypertrophy, hyperplasia, hemorrhage leading to an increased prevalence of parasites in gills of catla was seen from August to January. The result are in conformity with the findings of Chandra et al. (2012) who observed that mild hypertrophy and hyperplasia in primary gill lamellae and necrosis in secondary gill lamellae with parasitic infestation in carp in the months of October to February. The associated parasites with pathological signs in fish of present study were also supported by the findings of Ahmed et al. (2005) and Chandra et al. (1997). In contrast, the condition improved by February and March. In a clinical survey, Ahmed et al. (1998) observed loss of primary and secondary gill lamellae, clubbing, hypertrophy with protozoan cyst in gill of juvenile Indian major carp during August to January. The authors further mentioned that pathological signs started recovering in the months of February and March. Almost similar findings were also documented by Ahmed et al. (2009) and Hossain et al. (2008). 


\section{R. Das and K. J. Chandra}

However, marked necrosis, hypertrophy, hyperplasia, hemorrhage, clubbing, loss of lamella and presence of parasites such as monogenetic trematodes and protozoan cysts were attached to the gill lamellae of the fish in all ponds during November to January. This result was also similar with the findings of Hoque et al. (1999) and Islam et al. (1999). However, in the present study the gill pathologies like, loss of primary and secondary gill lamellae, hypertrophy, necrosis, haemorrhages and clubbing were found to be healing stage in the investigating carps from February to March. Recovery of loss of secondary gill lamellae, clubbing and hypertrophy of Indian major carps were reported by Ahmed et al. (1998) during February to March. Patwary et al. (2008) and Parveen et al. (2005) identified almost similar pathological changes in gills of investigated fishes. Among the investigated organs of the present experiment, gill had an increased pathology and diversified parasites compared to the other organs. This is due to the fact that, gill serves as rich source of nutrients and is in constant contact with the external environment where parasites can easily settle and survive.

Histopathologically, it was observed that, skin and muscle of fishes were normal in the months of March to July. Chandra et al. (2012) observed that skin and muscle of Catla, Rui and Mrigal had almost normal structure during April to July. Pathological signs such as number of parasites in skin and muscle of fish increased both quantitativly and qualitativly during August to January, whereas, it was in healing stage during February to March. Roy et al. (2006) worked on Puntius sophore, Mastacembelus pancalus and Nandus nandus collected from beel and noticed partial or total loss of epidermis and dermis, dermal splitting, necrosis, pyknosis, vacuolation, hemorrhage and presence of parasites and fungal granuloma observed mainly in skin and muscle pathology from August to January. In the present study, weak body, rough skin, deep ulcer and gray brownish color of the body susceptible to ectoparasitic (protozoa, monogenea and crustacea) infestation were observed in December to January. However, in the present experiment pathological signs and parasitic infestations highly increased in November to January. Akter et al. (2006) mentioned rough skin, weak body and gray brownish color of the body in C. punctatus, M. tengra and H. fossilis during winter months. Ahmed and Haque (1999) found that clinical signs like gray white necrotic areas were recovering stage in February, March and April in various carp species of Bangladesh. Histologically, it was observed that, partial or total loss of epidermis and dermis, dermal splitting, necrosis, pyknosis, vacuolation, hemorrhage and presence of parasites and fungal granuloma mainly in skin and muscle pathology from August to January. Almost similar changes were observed in rest of the months with a reduced severity and intensity. Skin and muscle were also severely affected in fishes obtained all ponds towards December and January. The result coincided with the finding of Chandra et al. (2012) who observed that pathologically, skin and muscle were almost normal structure in carps during summer seasons. Whereas, marked pathology such as loss of epidermis and dermal splitting, necrosis and hemorrhage with parasite were seen in rainy and winter season.

Histologically, it was observed that, structure of liver and kidneys were almost normal in summer season (April to July). During rainy season (July to October), mild hepatocytic necrosis, pyknosis and vacuums were found in a few places of liver. Almost similar pathological signs were presence of necrotic kidney tubules, hemorrhage and vacuolation in kidney structure during the period. Akter et al. (2009) observed mild affected liver and kidney with haemorrhages, necrosis and vacuums of A. testudineus during rainy season. Akter et al. (2006) also observed very few vacuoles, hepatic necrosis and disintegration in liver and kidney of $C$. punctatus, $H$. fossilis and $M$. tengara during the same period. An increased pathology was found in the internal organs such as liver and kidney during winter season (November to February). Severe necrosis, hemorrhages, hypertrophy and pyknosis along with the presence of dense protozoan cyst and fungal granuloma were observed in liver and kidney during the period. Hossain et al. (2009) worked on small indigenous species (SIS) from fish markets of Mymensingh and observed that fishes were severely affected during the months of November to January. The authors noticed necrosis, vacuums, haemorrhages, fat droplets, hypertrophy, hyperplasia and pyknotic cells with protozoan cyst and fungal granuloma in liver and kidney of the investigated fish. These findings were almost similar with the works done by Ahmed et al. (2009). In histological sections of liver and kidney, protozoan cyst was observed along with necrosis, pyknosis, hypertrophy and hemorrhages in the investigated samples. Similar pathological signs of liver and kidney were mentioned by Chandra et al. (2012) and Ahmed et al. (2009). Ahmed et al. (2006) stated that histological tissue section in gill of B. gonionotus and kidney positively confirmed massive infection of histozoic myxosporean, Myxobolus sp. Presence of fungal granuloma in the kidney of Catla catla were observed by Hoque et al. (1999). Parveen et al. (2005) recorded most of the fishes of Oxbow lakes were severely affected fungal parasites in pancreas, liver and kidney during the months of December and January.However, in February and March improved structure of liver and kidneys were observed. 


\section{CONCLUSION}

Pathologically, it was mentioned that during colder months, the fishes of Pvt. Farms were more affected than the fishes of Govt. farms. The evidence of more pathological symptoms in the fish of Pvt. Farms were due to fact that juveniles were not properly quarantined and provided poor management practices. Moreover, the farm authorities used different varieties of chemicals as a means of treatment for the juveniles of Catla. Thus, it could be suggested that more precautionary measures would necessary to be carried out in both the fish farms to prevent and control diseases in order to obtain healthy fish. Proper quarantine measures should be carried for the fish. Fry should be properly conditioned and treated before stocking. Indiscriminate use of medicines should be stopped during disease outbreak and in this regard opinion from experts should be desirable (if necessary). The supplied feed should be appropriate for the species and routine water quality parameters should be checked. Incase of disease outbreak, either facility for disease diagnosis should be introduced or affected fish should be brought to the disease diagnostic laboratory. Success of the implementation of various fisheries development program depends to the extend, on the intensification of fish disease research, as the improvement of fish yield can be achieved from healthy fish stock. It is thus expected that from such attempts, fish production from potential close water bodies of Bangladesh would be increased to a great extent and therefore, national economy would be uplifted to a standard platform.

\section{ACKNOWLEDGEMENT}

The authors thank the National Agricultural Technology Project (NATP): Phas-1, Project Implementation Unit (PIU) of BARC for financial support for conducting the research work.

\section{REFERENCES}

1. Adhikary RK, Mostafa ZB, Saha A and Shah MS (2009). Growth performance of Indian major carp in integrated culture system. Bangladesh Research Publication Journal 2: 361-370.

2. Ahmed GU, Akter MN, Nipa SA and Hossain MM (2009). Investigation on health condition of a freshwater carp, Catla, Rui, and Mrigal from Pvt. Farm, Mymensingh, Bangladesh. Journal of the Bangladesh Agricultural University 7: 419-424.

3. Ahmed GU, Gosh K, Islam MA and Tazkir-Uz-Zaman AKM (2006). Observation on health status of a juvenile exotic carp Barbodes gonionotus from different farming systems of Bangladesh. Progressive Agriculture17: 185192.

4. Ahmed GU, Haque MM and Hoque MJ (1998). Gill pathology of juvenile carps in nursery ponds. Bangladesh Journal of Fisheries Research 2: 63-67.

5. Ahmed GU and Hoque MM (1999). Mycotic involvement in epizootic ulcerative syndrome of freshwater fishes of Bangladesh. A histopathological study. Asian Fisheries Sciences 12: 381-390.

6. Ahmed GU, Parveen R and Lokman MA (2005). Seasonal variation of diseases of some small indigenous fish from Oxbow lake fisheries of Bangladesh. Pakistan Journal Zoology 37: 53-59.

7. Akter MN, Ahmed GU and Hossain MS (2009). Seasonal variation of gill pathology of a climbing perch in lake fisheries of Bangladesh. International Journal of Animal and Fisheries Science 2: 208-213.

8. Akter S, Ahmed GU, Roy MK and Akter N (2006). Investigation of the disease of some small indigenous fish species from Ailee bed, Mymensingh. Progressive Agriculture 17: 219-225.

9. Austin B and Austin DA (1987). Bacterial fish pathogens: Diseases in farmed and wild fishes. Ellis Harwood, Chichester. pp. 231-256.

10. Banerjee $\mathrm{S}$ and Bandyopadhyay PK (2010). Observation on prevalence of ectoparasites in carp fingerlings in two districts of West Bengal. Journal of Parasitic Diseases 34: 44 - 47.

11. Banu ANH and Khan MH (2004). Water Quality, Stocking Density and Parasites of Freshwater Fish in Four Selected Areas of Bangladesh. Pakistan Journal of Biological Sciences 7: 436 - 440.

12. Bhuiyan AS, Akther S and Amena NE (2010). Seasonal occurrence of parasites of the major carp, Cirrhina mrigala (Hamilton) collected from Rajshahi, Bangladesh. University Journal of Zoology of Rajshahi University 29: 47-50.

13. Bhuiyan AS and Musa AM (2008). Seasonal prevalence and intensity of infestation by the ectoparasites in carps relating to physico-chemical parameters in some ponds of Mymensingh and Bogra districts of Bangladesh. Bangladesh Journal of Scientific and Industrial Research 43: 411-418. 
14. Chandra KJ, Basak PK and Das DR (2012). Histopathological observations of farmed carp fingerlings of Mymensingh area. International Research Journal of Applied Life Sciences 1: 101-113.

15. Chandra KJ, Islam KZ and Wootten R (1997). Some aspects of association and development of Lytocestus indicus moghe in catfish, Clarias batrachus. Bangladesh Journal of Fisheries Research 1: 3 1-38.

16. Hoque MA, Ahmed GU, Rashid H, Sabur MA and Islam MJ (1999). Histopathological study of EUS in an Indian major carp, Catla catla. Bangladesh Journal of Fisheries 22: 85-91.

17. Hossain M D, Hossain M K, Rahman M H, Akter A and Khanom DA (2008). Prevalence of ectoparasites of carp fingerlings at Santaher, Bogra. University Journal of Zoology of Rajshahi University 27: 17-19.

18. Hossain MD, Hossain MK, Rahman MH 2007: Water quality parameters and incidence of fish diseases in some Water bodies in Natore, Bangladesh. Journal of Life Earth Sciences 2: 27-30.

19. Hossain MM, Ahmed GU, Tazri Z and Haque MA (2009). Clinical and pathological investigation of diseases in some small indigenous species (SIS) from fish markets of Mymensingh. International Journal of BioResearch 9: 7-14.

20. Humason GL (1979). Animal Tissue Techniques. W.H. Freeman and Company, San Francisco. pp. 611.

21. Islam MJ, Ahmed GU, Islam T, Haque MA and Sarkar MGA (1999). Gill pathology of carp's disease from farming systems of Bangladesh. Bangladesh Journal of Fisheries 22: 113-118.

22. Jhingran VG (1976). System of polyculture in inland waters in India. Journal of Fisheries Research Board of Canada 33: 905-910.

23. Ling SW (1974). Key note address. $5^{\text {th }}$ Annual Workshop. World Mariculture Society pp. 19-25.

24. Parveen R, Ahmed GU and Ali ML (2005). Seasonal variation of diseases of some small indigenous fishes from Oxbow lake fisheries of Bangladesh. Pakistan Journal of Zoology 37: 53-59.

25. Patwary ZP, Faruk MAR and All MM (2008). Clinical and histopathological study of important air-breathing fishes. Progressive Agriculture 19: 69-78.

26. Rahman MM and Chowdhury MBR (1999). Incidence of ulcer disease in African catfish (Clarias gariepnus Burchell) and trial for its chemotherapy. Bangladesh Journal of Fisheries Research 3: 193-200.

27. Roy MK, Ahmed GU, Akter S and Akter N (2006). Study of health condition of small indigenous freshwater fishes of Ailee beel, Mymensingh. Progressive Agriculture 17: 201-209.

28. Shahjahan M, Miah MI and Haque M M (2001). Present status in the Jamuna River. Pakistan Journal of Biological Science 4: 1173-1176.

29. Uddin MS, Miah MS and Alam MS (1994). Study on production optimization through polyculture of indigenous and exotic carps. Bangladesh Journal of Training and Development 7: 67-72. 